\title{
Essay \\ Sociology's Role in the Teaching of Organizational Behavior in Higher Education. The Case of Hospitality Management
}

\author{
Jorge Ferraz $1,2,3$ (D) \\ 1 Interdisciplinary Centre of Social Sciences-CICS.NOVA, 1069-061 Lisbon, Portugal; jorge.ferraz@eshte.pt \\ 2 Estoril Higher Institute for Tourism and Hotel Studies, 2769-510 Estoril, Portugal \\ 3 CITUR-Centre for Research in Tourism, Estoril Pole, 2769-510 Estoril, Portugal
}

Received: 13 June 2018; Accepted: 10 July 2018; Published: 13 July 2018

\begin{abstract}
Teaching in universities, especially in management schools, is today orientated to solving-problems and operational skills' development, short-term productivity gains and to a vocational perspective. This represents an impoverishment of a deeper learning, an obstacle to the development of competences in a broader and integrative sense and the absence of a critical thinking practice. These are important tools to enhance in students and future managers, as specific social actors, abilities to act in a conscious, autonomous and long-term efficacious manner in society. This essay's objective is to problematize the role that sociology could assume in the overcoming of that impoverishment, namely within the curricular unit of organizational behavior in two ways. First, teaching the social and macro dimensions that contribute to explain organizational structuring and behavior. Secondly, enhancing reflexivity and contextualization on the practices and discourses of all social actors involved and disassembling the dominant ideological, naturalized and simplistic individualized view on the reality of labor, employment and organizations. This is especially relevant in hospitality management studies because the dominant discourse about hospitality organizations hide, under a hegemonic paradigm of naturalized and individualized explanations, the macro-social dimensions of its organizational culture, work conditions, employees' behaviors, management styles and market labor.
\end{abstract}

Keywords: sociology; organizational behavior; hospitality management; critical thinking; deep learning; competences; management studies; higher education teaching

\section{Introduction}

The main issue that we are dealing with is the role of sociology in higher education, especially in the organizational behavior curricular unit within management studies, with particular emphasis on hospitality management. That is, the role of sociology and its study subjects and specific teaching practices in the academic training for future managers that are specific social actors involved in a particular social practice [1]. Those study subjects and specific teaching practices are related with the understanding of human behavior of employees and managers within contemporary organizations, understood as social constructions. The present essay's goal is to contribute to the discussion about deep learning [2], critical thinking, pedagogies [3,4] and competences in a broader sense [5], and to problematize relevant theoretical subjects and some operationalization strategies when teaching organizational behavior for management students. These tasks should be seen as important for promoting an effective, autonomous and conscious social practice. This essay is also the result of personal reflection about experience of more than two decades teaching organizational behavior or psychosociology of organizations for hospitality management students. 
In the teaching and training in management studies and in the contribution given by sociology there are several elements that have gained relevance that are mainly related to the strategies of professionalization of the managers, which are operationalized in the structure and contents of the courses and curricular units, in teachers' qualifications and competences, and in the teaching-learning activities developed [6]. This dominant component of the teaching is part of a conception of a production of knowledge that devalues the search for knowledge per se, which is related with the ideal that academic knowledge contributed to the emancipation of individuals, valuing rather a way of producing knowledge that aims at immediate social application [7,8]. Thus, a 'technicist' model is emphasized, favoring presuppositions that constrain the approach of social and human science disciplines, namely, reducing them to the exaltation of the primacy of a technical rationality on which a management ideology is based [1].

Our purpose is to overcome this containment and reductionism. On the one hand, in the teaching and training of management students, to take into account the expert knowledge that sociology has to offer, as well as the knowledge of studies, thesis and scientific theories that have given an account of the reality in question and which have constituted the heritage of organizational behavioral discipline. On the other hand, it is important to go further and to train and analyze their applicability in concrete problematic situations, developing the sociological problematization of discourses, social situations and theories and also of the actors concerned (teacher, student, manager, employee, employer). That is, the critical contextualization of what is taught in the curricular unit and the reality it portrays and aims to understand, enhancing the ability of future managers to effectively and lastingly solve complex problems and to think critically, which is fundamental to combat a false atomization of the reality in question and the ideological naturalizations of the phenomena.

So, we will start by defining the role and meaning of sociology and its contributions to higher education training and its relation with the contemporary debate about knowledge, skills and learning.

Next, the curricular unit of organizational behavior will be presented, which is recurrent in management and business studies, highlighting its specificity, the nature of its objectives and the various analysis perspectives that shape it. Particular focus will be given to the contributions of sociology in the teaching of this curricular unit, what has been dominant, and what can be implemented within the framework of the potentialities of sociology.

Finally, the main factors characterizing the dominant view of management studies and, in particular, the case of hospitality management will be presented. Special importance will be given to the general reality of the work in hotels, identifying dominant attitudes and behaviors, and presenting the reality and logic of the labor market in tourism and hospitality and its relation to the discourse, ideologies and culture of those organizations. We will also present the dominant view about hospitality management produced by schools and hospitality organizations. It is in this articulated reflection and in the defense of the need to include such problematized contents in the curricular unit of organizational behavior that we establish the particular role that sociology can have here in achieving deep learning.

\section{The Sociology in Higher Education Teaching}

The role we discuss here for sociology is not limited to the teaching of specific sociology contents, its various theoretical frameworks and their respective concepts, methods and techniques that characterized the sociological research and their technical-expert knowledge, similar to any other graduate scientific education. Their contribution also involves thinking and practicing sociology-alongside other social sciences-as a scientific discipline essential for understanding the complexity of social reality and as knowledge and practice that enriches conscious, critical and autonomous human action-that is, reflective practice and knowledge.

We have two dimensions, inseparable and entangled: The nature of what we want to achieve with the teaching and what knowledge, competences and/or skills to promote; the role of sociology in this process. 
As a first dimension, we have the discussion of the development of competences in the broader and more integrated view presented by Perrenoud [5], which configures a crucial perspective to equate here the role of sociology in higher education. That is, developing a high-level of 'know-how' - not reducible only to operational techniques-integrating varied cognitive resources in the treatment of complex situations, rejecting the dichotomy or mutual exclusion between skills and abilities, on the one hand, and knowledge on the other [5]. It is a question of overcoming the mere learning of techniques and the utilitarian logic of problem solving, however complex they may be, implying a general culture-critical, we would say-essential for preparing the social actors for their full autonomy as effective professionals and citizens. Professionals and citizens which practice reflexive thinking on subjects and actions are able to cope with social change and to be active participants in building the world. Actors who analyze, establish relations, problematize, criticize, act, transform, and generalize [5].

This question immediately points to the discussion of types of knowledge. Cognitive sciences have mostly focused on two main types of knowledge, presenting them as poles of an irreducible dichotomy that needs to be overcome, looking for their permanent integration [9]. We speak of procedural knowledge versus declarative knowledge. The first one, understood as the know-how-to-do a task and the techniques and procedures necessary to solve a situation; the know-how. The second one, as the knowledge about the tasks and techniques or the situations involved; the knowledge-about. With one we learn to do, with another, we know the facts and theories related to the subject. Teaching and training should seek the knowledge of which can be seen as: Integrating and surpassing the knowledge about and the knowledge how; and involving both the knowledge and skills that can be explained or demonstrated and the implicit or intuitive knowledge that does not directly manifest itself, is inferred and can be activated in action, and that is urgent to understand [9]. Such knowledge must be built upon problems that link a limited context of application with a general context, rather than the mere study of a list of thematic topics [9].

This rejection of the simplified and irreducible dichotomy is also, in another angle to the problem of teaching and training, what Perrenoud [5] proposes, by emphasizing a reflexive, critical and capable know-how, capable of integrating and contextualizing the learning outcomes in a wider scope of the knowledges and relatable social and technical realities.

We see here a path, consonant with a proposal of deep learning, implying connection between observed ideas, conclusions and patterns; reflexive thinking on the learning process and its context; integration of knowledge transmitted and learned in systematically articulated conceptual frameworks; relationships between new ideas and knowledge with previous knowledge and experiences [2].

In contemporary proposals for teaching and learning objectives and contents in universities, the most important word is 'competences'. However, for us, it often contains a fallacy: That of reducing itself to promoting skills and some sort of operationalism, more directly related with procedural knowledge, competence that is, in which, according to Barnett, "competence is expressed by the reliable performance of a behavior to a level of measurable efficacy against a predetermined standard" [9] (p. 1390). If, on the one hand, the teaching in universities has progressively abandoned the academic arrogance towards the outside world with a democratization of the power to state, the 'truth' and a general opening to the problems of society, on the other hand, this has been done through the overwhelming primacy of operationalism. The universities have been adapted to the logics of the entrepreneurial technostructure and the academy has become a mere marketplace and the students are seen as consumers of the service provided, reducing the vocabulary relative to "the critique of understanding and wisdom, which undermines its ability to work on behalf of the public good in ways that transcend the promotion of short-term gains in economic productivity" [9] (p. 1390).

Even when one assumes the goal of stimulating creative thinking and action in solving complex problems, it appears to be dissociated from-and even in dichotomous opposition to-reflexive critical thought [4]. We lose "understanding, wisdom and critique", reducing the learning resources that are important for the understanding of the real, which implies: going beyond immediate and short-term 
solutions for problems; the assessment of situations in a fuller context; and stimulating a kind of thinking that overcomes a mere "ability to flexibly and creatively solve problems defined by some more powerful person or institution" [9] (p. 1390).

The opposition between vocational studies (with an operational and professionalization focus) and liberal studies (home of a reflexive tradition that, at the same time, has often been closed to an intervention in everyday life)—especially the primacy of training in creative problems oriented to the logic of business-deprives students of the ability to think critically about the societal context and organizational reality, as well as about their own roles as managers [9].

It is the materialization of a dominant common-sense discourse about competencies, devaluing the intrinsic value of knowledge by forcing a fierce opposition between the knowledge of theories, frequently and erroneously identified with contempt for intervention in the social world, and promoting a knowledge based on skills, without concerns for reflexivity and critical thinking and with the understanding of the whole picture, vocationally oriented for the short term. This is a vision that is miles away from what Perronoud [5] says when he speaks about skills and competences and misses crucial premises of the deep learning presented by Sawyer [2].

As a second dimension, and more specifically related to the role and uses of sociology in higher education, we must emphasize the notion of pluralism and multiplicity of perspectives and discourses in the understanding of the social real offered by the social sciences; recognize the diversity of paradigms that are a normal trait of sociology; bear in mind the complex relationship between the integrated and complex nature of reality and the fragmented and partial nature of scientific knowledge; develop critical reflexivity about ourselves as socially situated producers of discourses that name and explain the reality; emphasize the social nature of the phenomena of human societies, avoiding false naturalizations of what is social; and clearly state that social processes are not reduced to decisions of individual actors, nor to understandings of human action merely based on possible individual determinants [10].

"The respect for this pluralism is shaped by the conception of social/individual relationships that excludes unilateral and dogmatic responses", based on the idea that "social reality is indivisible and social phenomena are total social phenomena (Mauss). All facts are always complex and multidimensional and may be grasped from different perspectives" [10] (p. 3).

We mean to attribute a central role for sociology in the understanding and the development of a critical and reflexive pluralism, scientifically based and breaking with common sense, that does not forget the social roots of human knowledge and human action. Thus, we understand that sociology plays an important role in the objectives of the teaching and training proposed above, since it is in its nature and in the nature of the object and of the subject of study and practice the permanent problematization and questioning of naturalized existing truths and their interpreters. In the same way, we understand that sociology can contribute to the development of competences in a broader, transversal and integrated sense, such as Perrenoud [5] proposed, that it could be a social practice (of the expert type or not) capable of associated itself with much more general and contextual problems and realities.

Therefore, we asked for a training and teaching strategy that emphasizes the potentialities of reflexivity, that is, the capacity of individuals and groups to reflect on themselves and others. We understand that sociology can foster in future hospitality managers a permanent capacity for self-reflexivity on management as an expert and professional activity, a social practice and system of representations being produced within, about and on hospitality organizations, as a space of conflicts of interests, power games, configurations and social logics, institutionalization of practices and discourses, and also their ideologies. In order to achieve this objective, it is important to make students aware of the importance of the diversity of integrated and articulated sociological competences: theoretical, methodological, relational, reflexive and operative. These "competences constitute a mediating instance between knowledge as 'products' (coming from early sociological work), 'contents' (of training and teaching programs in sociology) and professional action" [6] (p. 54). 
This is a vital issue in curricular units of organizational behavior in hospitality management studies. First of all, by the scientific matrix of the curricular unit, where sociology has a strong role, even in the sole realm of the expertise training where reflexivity is absent. Second, because the dominant valorization of an intense operationalism and an increased demand for creativity in the resolution of problems is frequently dissociated from critical thinking. Third, to assess the socio-historical and discursive reality of hospitality and hospitality management, both as organizational universes and higher education subjects.

\section{Organizational Behavior as Academic Curricular Unit and Scientific Field. What Role for Sociology?}

For Miner, organizational behavior "it is a social science discipline ... that has had its intellectual home in business schools (...) having its origins in the middle of twentieth century" [11] (p. 3), identifies two dimensions despite the blurriness of its frontiers: The behavior and nature of the people in organizations and the behavior and nature of the organization in its environment. Miner also speaks of two types of theories in organizational behavior: The micro, focused on individuals and small groups, closely linked to psychology, and the macro, with the focus on the organizations themselves and their environment, for which sociology has assumed the main role. However, beyond this traditional distinction we have seen in recent years, the emerging of a "meso theory (...) as concerning the simultaneous study of at least two levels, where one level deals with individual or group processes or variables, and [the other] ( . . ) level deals with organizational processes or variables, and bridging or linking propositions are set forth to relate the two levels" [11] (p. 11).

Thus, organizational behavior is the "multidisciplinary field that studies the behavior of individuals in organizations, as well as the structure and behavior of organizations" [12] (p. 30). For the three levels of the analysis and associated social sciences, we have: Micro level, based upon the resources of psychology and clinical psychology; meso level, counting mainly on the use of social psychology; and macro level, where sociology, anthropology, history, politics and economics are crucial [12].

Other authors, preferring to use the term "psychosociology of organizations", associate the three levels of analysis to the individual, group and organizational dimensions, for the study of which they point out four main scientific disciplines: social psychology, sociology and anthropology [13].

This multiplicity of used social sciences derives from the nature of the reality in question, simultaneously complex and one, for the understanding of which the isolated use of only one kind of social science is insufficient [13]. Cunha and Rego [12] mention the schizophrenia of organizational behavior because it oscillates between the two main sciences that are most used, psychology and sociology, understanding that, although each one is more adequate to a specific level of analysis than another, they are mainly interdependent and complementary.

Organizations are social constructions and, like the behavior of human beings, are complex and multifaceted realities, involving a diversity of rationalities, from the technical-systematic and technical-economic to the logic of societal organization and its institutions, through the psychosocial dimension of interpersonal relations [12]. The main hallmark of the reality and the study and understanding of organizational behavior is thus the interdependent diversity of scientific disciplines.

Another issue is related with theoretical paradigms. The field of study and the academic teaching of organizational behavior has to deal with the diversity of paradigms that each of the relevant social sciences has to offer when we try to analyze and understand the reality in question. The scientific and social views on organizations, shaping their reality, incorporate a huge diversity of images that refer to different and often contradictory worlds. In this regard, we can see the diversity of images and metaphors that can be built on organizational reality [14]: among others, prison, machine, system, symbolic-cultural and organic. Cunha and Rego propose paradigmatic diversity in the study of organizational reality, the construction of a "meta-metaphor of the organization as an amalgam", without invalidating the validity of the piecemeal perspective that each perspective brings [12] (p. 46). 
As for the actual teaching of organizational behavior in management and business schools, the dominant model tends to present the subjects fragmented by topics, organized into separate functional areas, rather than an integrated study centered on the complexity of the problems to be solved [15]. Although the study that concluded this was centered on full-time U.S. MBA programs, the authors say that, despite scarce data, the other few existing studies point to a similar reality in other parts of the world. As for the contents of the curricular unit, the most taught topics are leadership, group dynamics and motivation, being organizational citizenship behaviors, absenteeism and labor turnover, social exchanges, fairness, justice, and trust and identity which is the least (or almost nothing) addressed [15]. At an intermediate level we have, among others, topics such as power and politics, performance, change management, communication and decision making [15].

Looking at a study like this, and also on what are the contents of relevant organizational behavior manuals and the frequency and weight of each of their topics [11-13,16], we observe a clear predominance of a micro perspective, followed by an intra-organizational focus. Further examples of the predominance of the micro perspective can still be perceived in the way certain themes are approached, whether they are frequently studied or not. We present two themes: leadership and organizational citizenship, one that is very much addressed, the other being scarcely studied.

Examining the literature that studies leadership (and management) in an organizational context, and with the relative exception of perspectives that emphasize cultural and symbolic dimensions and identity issues such as those represented by the work of G. Hofstede, E. Schein or R. Sainsaulieu [12,13,16-18], we find very little attention on understanding the social roots of the process of legitimizing leadership. The same is true when we think of understanding the manager and also the leader as an individual that also represents a social actor emerging in a certain society. The great majority of theories accentuates a micro and individualizing vision, based on the characteristics of the leader or the contingencies that result from group processes, power plays or the structuring of intra-organizational tasks. What predominates is a perspective that associates the issues of leadership and management with a technical discourse or with personal qualities [1].

As far as organizational citizenship studies are concerned, they often focus on individual and psychological perspectives, especially reporting on individual qualities and behaviors. In this case, we see topics such as sportsmanship, cooperation, organization advocacy, self-improvement and their crucial role to the well-being of individuals. Also, in studying which practices the organization can or should develop as an enhancer of such behaviors, we see as main topics, integrity, procedural justice, fairness or trust. And finally, we observe the concern with its impact on the development of a psychological contract between people and organization, the physical and psychological well-being of employees and the increase of productivity [12,19-21]. However, it is almost never seen in such researches, as Casey [22] discusses, an understanding on the emergence of such issues in relation to the society in which we live, nor is it discussed how the societal organization and organizations promote or limit the values and practices of citizenship and its promotion in the wider sense with sociopolitical, cultural and socioeconomic impacts.

Despite the diversity of scientific disciplines and perspectives, as well as the recognition of the plurality of paradigms, when we analyze the topics of organizational behavior and relevant bibliography and authors [11-13,16], the reflexivity and contextualization proposed in the first point of this essay is almost absent. The exceptions are some contributions from the school of institutionalism, the marxist perspective of Braverman and the studies that propose the idea of the economic corporation as a social institution $[12,13,23]$.

In other words, very little attention (and even lesser in integrated and interactive manner) is payed to relevant issues such as the role of economic private corporations on building society and identity $[17,23]$, its emergence in a given societal configuration and its relation with autonomy, freedom and the identity of people within and outside organizations. We also miss discussing the rising and the implementation of discourses about what is management and the manager as social practices and social actors. Contextualizing the logics of a specific labor market and the social, political and economic 
dimensions of their demographic movements, as well as outlining the sociopolitical and socioeconomic history of the activity sector under study could be important for the understanding of the behavior and commitment of the employees, organizational culture and management policies. The same could be said about the lack of a generic understanding of the social nature of contemporary labor and its impact on organizational discourse, practice and on the construction of society and the identity of each individual or group. Enhancing the relationship between organizational models, discourses and societal organizations at political, economic, cultural, educational and ideological level beyond the anti-capitalist perspective, is also important.

In fact, an integrated and problematic approach to the various topics that usually appear in the curricular unit of organizational behavior is rarely exercised, and there is a huge absence of the second dimension of the role that we ask for sociology in higher education, namely the promotion of reflexivity, contextualization and problematization of truths given as unquestionable. Such a task is essential to disassemble the false neutrality of claimed technical rationality of organizational processes and the naturalization and individualization of processes and realities that are also social. It also avoids the reduction (which can be impoverishing, simplistic and even socially innocuous) of critical understanding and deconstructive thinking to a one-dimensional reading, mainly the rejection of existing society or capitalism and its processes.

The task we propose above becomes even more pressing when we are dealing with teachings, trainings and organizational environments that emphasize skills development and the learning of practices directed at problems solving that are pre-formulated and pre-defined, without critical thinking and with no contextualization of processes and individual and collective actors. All of this accentuates operational principles and a vocationalist discourse. These principles and discourses are supported by the primacy of theories that explain that human reality and people's practices and beliefs are mainly based on individual dispositions and simple psychological characteristics. This is the case of management teaching, training and, especially, hospitality management. First of all, because hospitality management is a subgroup of business and management education where schools are pressured to develop and train the skills that organizations want, preferring the ability "to do" (practical) instead of "know" (theoretical) and where cognitive and intellectual skills are orientated to the "growth of a set of personal and interpersonal practical skills, e.g., self-awareness, problem-solving" [24] (p. 147). Secondly, because the dominant discourse reflects the hegemony of individual and psychological arguments as an explanation for organizational behavior [25,26].

\section{The Contributions and Contents of the Curricular Unit Organizational Behavior for Critical Hospitality Management Studies}

Defining hospitality, we begin to say that it is an organizational entity and the set of services, products and techniques intended to provide accommodation, food and beverage and to participate in taking care of the leisure, animation and well-being of people in mobility, especially people away from home.

But there is more: Hospitality is also a space of social and economic exchange, it configures forms of social control of guests and hosts, participates in the definition of what is a stranger and how to deal with it; serves as a metaphor of the relationship between cultures; shapes the contents of the idea of being at home in a distant place; contributes to the anthropological concept of hospitality; aims to participate in the definition of the memorable memories of the life of the guests and has an important role in framing practices and discourses about contemporary physical, psychological, social and cultural mobilities [27-29]. All of this signifies the presence of social images, metaphors and constructions framing the meaning and reality of hospitality and of the hospitality industry, which is reflected in its study and it shapes what happens to the people in there.

Thus, hospitality management is a technical and a social practice in the realm of hospitality, seen in the broader sense. It is more than the mere managing or coordination of the services and products provided by the hospitality industry or of the tasks and qualifications of its employees. 
Characterizing the state of the studies on hospitality and, in particular, on the hospitality industry and its people, we see great insufficiency and even invisibility [26,27]. Being an area of labor which places great emphasis on the human factor presented in the relationship host/employer-guest/client, the lack of studies and teaching on its symbolic and cultural dimensions and on the related social and psychosocial issues is an important gap in the training of future managers [28,30,31]. With the exception of management and business schools and their technical focus, the worlds of hospitality, the hospitality industry and the university have been back facing each other.

Another subject to bring here is the understanding of the hospitality industry and their processes by the traits of contemporary labor.

The main characteristics of contemporary labor are the fragmentation and individualization of labor and employment, the establishment of highly plastic and transitory forms of business organization and labor relations, and the end of long-term employment [32-34], with a strong impact on people's citizenship, autonomy and identity.

The capital-labor relationship nature and how it shapes the world of labor becomes invisible [33]. Simultaneously, we see the return of a naturalized technocratic vision about the organizational processes and the power relations that are inscribed there; individual competition and the need for constant technical-professional requalification are represented as the dominant and normal characteristics of this process, replacing the previous centrality of tensions between social groups (such as the example of tensions between social classes) expressed in the workplace [32-34].

Another important trait is the increasing primacy of emotional, relational and intellectual factors that are presented as important requirements for work and as the main productive resources in a process of 'servicialization'; working is above all to create a service for a consumer, reproducing in all spheres of production and economic activity the paradigms of the service industry [32].

Finally, we observe a permanent renegotiation between time-space of work and non-work, and the blurring of its frontiers [33].

Concerning the work activities in the hospitality industry, the issues of mobility, individualism, insularity of the work experience, and the relational and emotional characteristics of employees are crucial. Work in the hospitality industry is characterized by high mobility and turnover of employees and high seasonality associated to difficulties on recruiting competent and committed personal (specially at entry level) and to the employment of marginal, gendered and disadvantage labor [35]. The jobs are mainly of unskilled and semi-skilled nature with a low level of specialized training and, at the same time, characterized by a high transferability for other professions or jobs $[25,26,35]$.

The hospitality industry offers, in general, poor conditions of employment with long and unsocial working hours, low wages, isolation, unbalanced work-personal relation and family time, and high stress and frequent burnout $[25,26,35]$. On the other side, we have employees with low empowerment and participation and a low level of unionization $[25,26,35]$.

However, we must avoid excessive generalizations. On the one hand, the characteristics mentioned above generally do not apply to managers and there is some diversity of social statutes and working conditions between countries.

For example, in developing countries, working in the tourism and hospitality sector is prestigious and offers more opportunities for mobility and social status than many other options available to the population [36]. More, if we consider the question of mobility, it can act as a central attraction for many people, young people in particular, that choose to work in the tourism and hospitality industry because it can be a possibility of changing horizons and environments and to interact with people coming from different societies [37]. The same could be said about the transferability of skills, that could represent an opportunity for disadvantaged labor, minorities and emigrants in gaining access to the labor market or to enter a new country and, later, changing to better and more stable work [35-37].

Although the majority of the mentioned characteristics do not apply to managers, there are some, such as unbalanced work-family relationship, high stress and burnout, as well as working with antisocial schedules and rhythms, that they have in common with the rest of the employees [38,39]. 
Characterizing the mains intrinsic traits of service provided by the hospitality industry we have: intangibility, inseparability and heterogeneity or separability [40]. Intangible services are services where the behavior, appearance and personality of the employee are the central perceived value; inseparability means the simultaneity of production and consumption of the services provided; and heterogeneity results from the fact that different people could perform the same service differently [40]. One more time, the question of the interpersonal factors in the guest-host relationship becomes crucial $[36,40]$. However, once again, we should be careful with generalizations and 'buzz words', especially when the hospitality industry claims the centrality, almost the hegemony, of the host-guest or employee-customer personal interaction. And what about the invisible workers frequently working alone or in isolation? The ones who clean rooms, floors and pools, wash dishes and laundry, do the maintenance of underground machinery? Where are they? What percentage do they represent in the whole of a hotel workforce?

Another topic to be understood is the way the industry organizes itself. It is an industry marked, in the last 20 years or so, by a great process of globalization and by a complex and nonlinear reorganization of the structure of control, command, production and investment [41]. On one side, we saw a fragmentation of the business chain-value, alienating services and areas of activity (such as the outsourcing of laundry services, equipment maintenance and even the management of the corporation on itself); on the other side, we see the composition of a new chain-value characterized by the emphasis on financial control along the decentralizing of production, similar to what has happened in other industries [42]. Therefore, we saw new types of industry integration: vertical, horizontal and diagonal [42].

Vertical integration means a new incorporation of the various services of the tourist activity (from the sale of trips to services of hospitality and cultural animation) in a multi or transnational corporate group, where the different corporations maintain their specific name and relative autonomy in the production [42].

Horizontal integration is the aggregation of different corporations of the same branch of activity, targeting different market segments and/or doing multi-branding [42].

Finally, diagonal integration is the integration of hotel units (hotels) into a large financial corporation, alongside construction companies, oil drilling, telecommunications and financial services [42].

In addition, we also have the dematerialization of the activity exemplified by franchising, the sale of management contracts or the brand management [42]. The vast majority of innumerable small businesses, which are the main feature of the hospitality industry, are increasingly integrated into these large conglomerates, which deal primarily with financial and strategic control and decisions.

About cultural organization, attitudes and behaviors in the hospitality organization, the generality of studies mention: social isolation, individualism and low cooperative work, emphasis on informal and interpersonal rewards, sociocultural diversity, customer relationships orientation, positive evaluation of individual and interpersonal skills, service uniqueness and distinction, personal and directive style of leadership - even authoritarian, and low motivation of the employees [26,28,35]. The hospitality industry presents itself as a vocational world, where work experience and psychological and individuals factors, such as personal motivation and resilience, are the crucial factor to get the job done and to explain the labor mobility and the reality of working in hotels, accentuating the uniqueness of its domain $[25,26]$. Exceptionality, insularity, mobility and vocation are the key words.

Finally, what about the market labor for the hospitality and tourism industry? Is the mobility explained only by psychological traits? On the surface, seasonality says otherwise. The work conditions join another argument. In fact, the labor market for the hospitality and tourism industry is of a secondary and internally weak type; from low-skill specificity and specialization to unspecified hiring standards, through no clear promotion criteria, no continuous on-job training and no strategic human resources planning and management $[37,40]$. Identifying the most important social and demographics traits of a great majority of the workers in the industry, excluding managers, we have: emigrants, 
woman, ethnic minorities, young trainees from hospitality schools or young people between jobs or doing summer work [43,44].

Dealing now with the subject of hospitality management studies, a major concern was, and remains, "the degree of 'fit' between the curriculum and student development on the one hand, and industry needs on the other", accentuating a close relationship between school students and school administrators within the industry [24] (p. 155). This objective accentuates a vocational logic, the training for an occupationally circumscribed profession, maintaining a separation between a liberal (reflective tradition) teaching and vocational (operative and vocational) training, with a central focus on the last one [31].

For Morrison and Gorman [31] this is a problem in the education of future hotel managers, narrowing their training and skills, which is why they call for a break with this and emphasize the benefits for hospitality management theory and practices of a curriculum informed from a social science-based studies perspective. That curriculum could be based upon an already existing tradition of multidisciplinary research in hospitality such as: A sociological approach to the study of hospitality management; gender studies; the interrelatedness of the hospitality industry and outside world; philosophical issues dealing with hospitality as phenomenon and the role of hospitality in society; the politics of hospitality and their relation with democracy, citizenship, ethics; deconstructionism studies, and so on [31].

The development of critical management studies advocated here is essential to "learn not just how to be effective managers in the current tourism system, but also how to think about management as a social force." [3] (p. 1392). It offers an alternative to the dominant perspective in schools of hospitality (often framed as management and business schools), which opposes, as irreducible places, a critical analysis vs. a positivist view; a dominant thinking vs. a marginal and anti-system posture and the theoretical versus the operational; limits the knowledge as reflective practice; diminishes the ability to problematize established truths and hides the importance of the diversity of perspectives in management, teaching and researching in hospitality; and imprisons students in uncritical and simplified polar positions [4].

The enormous emphasis on technocratic training and operationalism in hospitality management studies contributes to giving students "a comforting sense of certainty that the world is, in fact, well understood" [3] (p. 1394). However, and ironically "such an approach may not really prepare students to make their way in a world that does not necessarily function on the principles of technical rationality but that the modern mind nevertheless insists on imposing on it" [3] (p. 1392), ignoring the complexity of social life and the fact that human beings are not reduced to an entirely predictable set of behaviors accommodated in the drawing of a technical diagram. In fact, accentuating technical rationality and ignoring its limits on the effective capacity to coordinate human actions is also dysfunctional for the economic productivity of organizations [3].

\section{Conclusions}

Our goal was to discuss and, consequently, present some proposals concerning the role that sociology can play in the teaching and training of future hospitality managers, particularly within the framework of the curricular unit of organizational behavior. Our essay pretends to leave an open door to a diversity of positions that different actors can and will take on the coordination of people in the labor organizations, assuming the plurality of levels of analysis, understanding and intervention, as well as the diversity of scientific disciplines and paradigms which they enclose. We claim that such positions are not an obstacle to management practices concerned with economic efficacy and productivity, even in the short term, but they allow us to go further, to constitute an affirmation of the manager's autonomy and awareness of what these practices imply and the role they can play in the wider world of human societies, including a critical reflection on the manager's own role. This is the place of deep learning and knowledge, which cannot ignore the development of critical thinking or 
forget the role of sociology in promoting critical reflexivity and the social contextualization of facts and actors and their practices and discourses.

Deep learning and the development of skills and competences that includes critical and integrated thinking and the ability to generalize and understand contexts and their relationship to an actor's actions and practices does not dismiss the important role played by the knowledge and training of theories and techniques concerning the issues of daily and operational activities related to people's behavior at work and short-term gains in productivity. That is, there is no intrinsic or essential contradiction with the important and effective social and professional practice in solving problems at work and in organizations involving productivity and well-being.

Thus, and as the usual contents of the curricular units of organizational behavior present, dealing with the behavior of people at work implies: Understanding what motivates them to be involved or not; what their needs are; how to lead them; what the dynamics of inter and intra-group processes are; how organizational, intergroup and interpersonal communication happens; the role and importance of ethical conduct; and the impact that these issues all have on the productivity of organizations and the well-being of their members. However, this is insufficient and sociology can play an important role in bridging this gap. This has partially been done by the contributions of the sociology of work and sociology of organizations. But, as we also mention, it is necessary to go further, because there are central issues that are not addressed-what is even more important is where the aforementioned sociologies of work and organizations do not exist in management studies programs.

So, management studies could include, in a problematized relation with those usual contents of organizational behavior, subjects such as: The characteristics of human labor in organizations in a given society, considered in general and then detailing for the type of organizations concerned; the dominant attitudes of employees, employers and managers in the organizations concerned and considering the diversity of situations; the understanding of the manager and management as social roles and actors; the organization of the sector of activity concerned and the way in which production and control are structured in terms of socio-political and socio-economic dynamics; the scientifically and socially constructed metaphors about the organizational world and as a space for building society; the characteristics and movements of the labor market that go beyond the mere identification of technical-economic variables and the assessment of qualifications, referring to an understanding of the socio-demographic and socio-economic dynamics which implies perceiving what type of social actors are present and why; the discourses and ideologies promoted by the organizations in question; the characteristics of the organizational culture, and the understanding of the contexts and actors involved in its determination.

From the above, and beyond what the usual contents of organizational behavior are, we see as most important and more easily integrated in the limited time that any curricular unit has, for example a semester with more or less 15 weeks, the following four suggestions. An initial topic, with theoretical and empirical examples about multidisciplinarity and the diversity of theoretical paradigms within each social science when dealing with organizational behavior and the resulting diversity of images about organizations. Second, discuss management as social practice and the manager as a social actor emerging in a specific societal configuration characterized by peculiar power structures and ideologies. Third, understanding socio-political and socio-economic characteristics of employment and market labors in a given societal configuration. And, finally, to increase students awareness to the fact that the creation, the shaping and the maintenance of organizational culture is also the product of power relations and complex social interactions.

A complementary task for exercising what we suggest here is proposing students the elaboration of a small paper about subjects that are dominant in our societies and frequently presented in a naturalized and non-problematic and non-contextualized manner. That paper should be based upon different scientific studies that present pro and against arguments and represents different social sciences and or paradigms. As examples we mention topics such as the meaning of human and intellectual capital, social responsibility, learning organizations, emotional work, capital-labor relations, entrepreneurship, 
organizational citizenship and labor democracy, the congruence between ethics, employees well-being and economic and financial issues. That paper could include a personal problematization about the role of managers when dealing with such subjects.

Moreover, it is very important that teachers practice and stimulate in students critical thinking about their roles and the subjects studied.

The hospitality management courses share with general management studies the ideology of technical operationalism, the centrality of the discourse of competences and skills, and the development of abilities in solving problems related to economic productivity. This appears in opposition to critical thinking and theoretical knowledge. That would be enough to justify our proposal. However, the issue here is even more important because of the hegemony of the discourses of vocationalism, individualism and psychological traits in the hospitality industry, which does not let us see the whole and complex nature of the conditions and characteristics of the work and of the labor market. The curricular unit of organizational behavior, such as the one that studies the behavior of people at workplaces and participates in the training of future human work coordinators, must not conceal a critical understanding of what such behavior entails and which will imply such coordination within a specific organizational framework, integrating and problematizing the various topics or items of their curricular content, combating the fragmentation and atomization of knowledge and practices. It also has special responsibility when it appears as the few curricular formations related to social science issues in a vast ocean of technical curricular units.

Without this, future managers, who are first and foremost citizens, become simple executors of techniques and procedures and reproducers of ways of analyzing and deciding that, at another time or place, will be ineffective. There is no enduring competence without theory, nor autonomous knowledge with effective and conscious social action without critical thinking and reflexivity. Developing all of this within the diversity of perspectives and paradigms, it is essential to act effectively and autonomously in a complex and one reality, impossible to be understood and experienced by a single view.

Funding: This research received no external funding.

Acknowledgments: The author acknowledges the comments and suggestions by this article's editors and three anonymous reviewers.

Conflicts of Interest: The author declares no conflict of interest.

\section{References}

1. Reed, M. Sociologia da Gestão. The Sociology of Management; Celta Editora: Oeiras, Portugal, 1997; ISBN 972-8027-59-1.

2. Sawyer, K.R. (Ed.) Introduction: The new science of learning. In The Cambridge Handbook of the Learning Sciences; Cambridge University Press: New York, NY, USA, 2006; pp. 1-16, ISBN 978-0-521-84554-0.

3. Belhassen, Y.; Caton, K. On the end need for critical pedagogy in tourism. Tour. Manag. 2011, 32, 1389-1396. [CrossRef]

4. Fullager, S.; Wilson, E. Critical pedagogies: A reflexive approach to knowledge creation in tourism and hospitality studies. J. Hosp. Tour. Manag. 2012, 19, 1-6. [CrossRef]

5. Perrenoud, P. Des savoirs aux compétences: De quoi parle-t-on en parlant de compétences? [From knowledges to competences: What are you talking about when we talk about competences?]. Pédagog. Collégiale 1995, 9, 20-24.

6. Costa, A.F. Será a sociologia profissionalizável? [Is sociology possible to professionalize?]. In Actas do Encontro Sociologia no Ensino Superior: Conteúdos, Práticas Pedagógicas e Investigação, Porto, Portugal, 6-7 Dezembro de 2002 [Proceedings of the Meeting Sociology in Higher Education: Contents, Pedagogical Practices and Research, Porto, Portugal, 6-7 December 2002]; Gonçalves, C.M., Rodrigues, E., Azevedo, N., Eds.; Faculdade de Letras da Universidade do Porto (School of Humanities of the University of Porto): Porto, Portugal, 2004; pp. 35-58.

7. Gibbons, M.; Limoges, C.; Nowotny, H.; Scwartzman, S.; Scott, P.; Trow, M. The New Production of Knowledge. The Dynamics of Science and Research in Contemporary Societies; Sage Publications: London, UK, 1994; ISBN 0-8039-7793-x. 
8. Magalhães, A. A Identidade do Ensino Superior. Política, Conhecimento e Educação Numa Época de Transição [Higher Education Identity. Politics, Knowledge and Education in an Era of Transition]; Fundação Calouste Gulbenkian: Lisboa, Portugal, 2004; ISBN 972-31-1087-3.

9. Scardamalia, M.; Bereiter, C. Knowledge building: Theory, pedagogy and technology. In The Cambridge Handbook of the Learning Sciences; Sawyer, K.R., Ed.; Cambridge University Press: New York, NY, USA, 2006; pp. 97-116, ISBN 978-0-521-84554-0.

10. Ferreira, C.M.; Serpa, S. Challenges in the teaching of sociology in higher education. Contributions to a discussion. Societies 2017, 7, 30. [CrossRef]

11. Miner, J.B. Organizational Behavior. Foundations, Theories and Analyses; Oxford University Press: New York, NY, USA, 2002; ISBN 0195122143.

12. Cunha, M.P.; Cabral-Cardoso, C.; Cunha, R.C.E.; Rego, A. Manual de Comportamento Organizacional e Gestão [Manual of Organizational Behavior and Management], 6th ed.; Editora RH: Lisboa, Portugal, 2007; ISBN 978-972-8871-16-1.

13. Ferreira, J.M.C.; Neves, J.; Caetano, A. Manual de Psicossociologia das Organizações [Manual of Psychosociology of Organizations]; Escolar Editora: Lisboa, Portugal, 2011; ISBN 9789725922972.

14. Morgan, G. Images of Organizations; Sage Publications: London, UK, 1986; ISBN 978-1-4129-3979-9.

15. Brown, K.G.; Charlier, S.D.; Rynes, S.L.; Hosmanek, A. What do we teach in organizational behavior? An analysis of MBA syllabi. J. Manag. Educ. 2013, 37, 447-471. [CrossRef]

16. Luthans, F. Organizational behavior. In An Evidence-Based Approach, 12th ed.; McGraw-Hill/Irwin: New York, NY, USA, 2011; ISBN 978-0-07-353035-2.

17. Sainsaulieu, R. Sociologie de l'Enterprise: Organisation Culturelle et Développement [Sociology of Corporations: Cultural Organization and Development]; Editions Presse Science Po et Dalloz: Paris, France, 1997; ISBN 2247020763.

18. Yukl, G. Leadership in Organizations, 6th ed.; Prentice-Hall: Upper Saddle River, NJ, USA, 2006; ISBN 9780131494848.

19. Lub, X.D.; Blomme, R.J.; Bal, P.M. Psychological contract and organizational cizitenship behavior: A new deal for new generations? Adv. Hosp. Leisure 2011, 7, 109-130. [CrossRef]

20. Moorman, R.H.; Blakely, G.I.; Niehoff, B.P. Does perceived organizational support mediate the relationship between procedural justice and organizational citizenship behavior? Acad. Manag. J. 1998, 43, 351-357. [CrossRef]

21. Ribeiro, N.; Rego, A. Does perceived organizational virtuousness explain organizational citizenship behaviors? Int. J. Psychiatry Behav. Sci. 2009, 3, 1103-1110. [CrossRef]

22. Casey, C. Organizations, workers, and learning: New prospects for citizenship at work? Citizsh. Stud. 2009, 13, 171-185. [CrossRef]

23. Parente, C. Sobre as teorias da empresa [About corporation's theories]. Sociol. Rev. Fac. Let. Univ. Porto 2005, 15, 165-216.

24. Barrows, C.W.; Johan, N. Hospitality management education. In The Sage Handbook of Hospitality Management; Brotherton, B., Wood, R.C., Eds.; Sage Publications: London, UK, 2008; pp. 146-162, ISBN 978-1412900256.

25. Wood, R.C. Working in Hotels and Catering; International Thomson Business Press: London, UK, 1997; ISBN 1861521855.

26. Wood, R.C. Organizational Behaviour for Hospitality Management; Taylor \& Francis Ltd.: Oxford, UK, 1994; ISBN 0750618302.

27. Brotherton, B.; Wood, R.C. The nature and meanings of 'hospitality'. In The Sage Handbook of Hospitality Management; Brotherton, B., Wood, R.C., Eds.; Sage Publications: London, UK, 2008; pp. 35-61, ISBN 978-1412900256.

28. Dawson, M.; Abbott, J.A.; Shoemaker, S. The Hospitality culture scale: A measure organizational culture and personal attributes. Int. J. Hosp. Manag. 2011, 30, 290-300. [CrossRef]

29. Lynch, P.; Molz, J.G.; Mcintosh, A.; Lugosi, P.; Lashley, C. Theorizing hospitality. Hosp. Soc. 2011, 1, 3-24. [CrossRef]

30. Bavik, A. Identification of organizational culture in the hospitality industry. In Tourism and Hospitality Management (Advances in Culture, Tourism and Hospitality Research, Volume 12); Metin, K., Kozak, N., Eds.; Emerald Group Publishing Limited: Bingley, UK, 2016; pp. 197-210, ISBN 978-1-78635-713-7. 
31. Morrison, A.; O'Gorman, K.D. Hospitality studies and hospitality management: A symbiotic relationship. Int. J. Hosp. Manag. 2008, 27, 214-221. [CrossRef]

32. De Almeida, P.P. Variações Sobre o Trabalho Moderno [Variations on the Modern Labor]; Editora Mundos Sociais/CIES/ISCTE-IUL: Lisboa, Portugal, 2012; ISBN 978-989-8536-09-9.

33. Castells, M. The Rise of the Netwok Society, 2nd ed.; Wiley-Blackwell: Chichester, UK, 2010; ISBN 978-1-4051-9686-4.

34. Freire, J. Trabalho, emprego e cidadania. [Labor, employment and citizenship]. Sociol. Rev. Fac. Let. Univ. Porto 2009, 19, 213-226.

35. Kusluvan, S. Characteristics of employment and human resource management in the tourism and hospitality industry. In Managing Employee Attitudes and Behaviors in the Tourism and Hospitality; Kusluvan, S., Ed.; Nova Sciences Publishers: New York, NY, USA, 2003; pp. 3-24, ISBN 978-1-62417-935-8.

36. Baum, T.; Kokkrannikal, J. Human resource management in tourism. In The Management of Tourism; Pender, L., Sharpley, R., Eds.; Sage Publications: London, UK, 2005; pp. 85-101, ISBN 0761940227.

37. Riley, M. Labor mobility and market structure in tourism. In A Companion to Tourism; Lew, A., Hall, C.M., Williams, A.M., Eds.; Blackwell Publishing: Malden, MA, USA, 2004; pp. 135-145, ISBN 9780631235644.

38. Mulvaney, R.H.; O'Neill, J.W.; Cleveland, J.N.; Crouter, A.C. A model of work-family dynamics of hotel managers. Ann. Tour. Res. 2007, 34, 66-87. [CrossRef]

39. O'Neill, J.W.; Davis, K. Work stress and well-being in the hotel industry. Int. J. Hosp. Manag. 2011, 30, 385-390. [CrossRef] [PubMed]

40. Kusluvan, S. Employee attitudes and behaviors and their roles for tourism and hospitality. In Managing Employee Attitudes and Behaviors in the Tourism and Hospitality; Kusluvan, S., Ed.; Nova Sciences Publishers: New York, NY, USA, 2003; pp. 25-50, ISBN 978-1-62417-935-8.

41. Hjalager, A.-M. Stages in the economic globalization of tourism. Ann. Tour. Res. 2007, 34, 437-457. [CrossRef]

42. Ferraz, J. Turismo e globalização [Tourism and globalization]. In Planeamento e Desenvolvimento Turístico [Tourim Planning and Development]; Silva, F., Umbelino, J., Eds.; Lidel: Lisboa, Portugal, 2017; pp. 79-92, ISBN 978-989-752-230-7.

43. Ladkin, A. Exploring tourism labor. Ann. Tour. Res. 2011, 38, 1135-1155. [CrossRef]

44. Zampoukos, K.; Ioannides, D. The tourism labour conundrum: Agenda for new research in the geography of hospitality workers. Hosp. Soc. 2011, 1, 24-45. [CrossRef]

(C) 2018 by the author. Licensee MDPI, Basel, Switzerland. This article is an open access article distributed under the terms and conditions of the Creative Commons Attribution (CC BY) license (http:/ / creativecommons.org/licenses/by/4.0/). 